\title{
IMPROVING THE CAPABILITIES OF WRITING NARATION OF JAPANESE LANGUAGE THROUGH THE DRAWING MEDIA IMAGE SERIES (ACTION RESEARCH IN SMK NEGERI 18 JAKARTA)
}

\author{
Nurainih \\ SMKN 18 Jakarta \\ nur.ainih@unj.ac.id,
}

\begin{abstract}
Abstrack
This action research aims to improve students' ability in writing Japanese narrative through the medium of series images. The subjects of this study are students of class XI Accounting at SMK Negeri 18 Jakarta, the year of learning 2016-2017. The research data was collected through observation, prates, collaborator notes, and final tests of each cycle. This action research model uses the research model of Kemmis and Mc Taggart action that is planning, action, observation, and reflection. This study was conducted for two months consisting of eight meetings in two cycles. Four cycles meeting I and four cycle II meetings. Improvements are made in each cycle and follow the post test at the end of the lesson. Research data were analyzed through qualitative and quantitative procedures. The result of the research stated that the students' ability in writing Japanese language narration in cycle I was only 68.5 and cycle II became 83.2. Based on that, the medium of the series image can improve students' ability in writing Japanese narrative.
\end{abstract}

Keywords: Writing, Narrative, Serial Drawing.

Learning Japanese language is inseparable from the four language skills of reading, listening, writing, and speaking. The learner's stage in studying these four abilities is closely related. The ability to write can not be separated by the ability to listen, read, and speak. Writing is the same with other language activities. This activity is the ability gained by practicing. Systematic, continuous, and disciplined practice is the key that is always advisable to be able to write. If in speech one must master the symbol of sound, in writing one should master the symbols or visual symbols and rules of the grammar. A writing can be fun to read when laid out well and correctly, so it can make a good sequence of words and sentences as well.

Writing is one aspect that must be mastered by language learners who function as a nonverbal communication tool. Writing is not limited by time and space. Writing can also be read anywhere, anytime, and by anyone. If someone likes to write, he or she will be interested in making essays. Conversely, if people do not like to write, he will not be interested in making articles even with any technique. In writing essays, students are required to have creativity and imagination. When writing essays, many students have difficulty because writing is a language skills that are considered complex. Writing is related to letters, vocabulary, grammar, and is required to be able to put ideas into writing.

In Japanese, the term making up a story or narrative is known as sakubun. Sakubun consists of two kanji namely, kanji pocket (作) which means "make" and kanji bun (分) which means "sentence". Sakubun literally means making sentences (Dahidi, 2004: 22). In learning Japanese, students are required to be able to speak the tongue correctly. Students are also required to be able to master the writing language. Therefore, sakubun becomes one of the learning that is controlled for the students who learn Japanese. The learning of writing sakubun (narration) is considered a difficult ability, both for students and teachers. Students feel difficult because they are required to be able to apply all linguistic materials ranging from the mastery of sentence patterns, vocabulary, and hiragana, 
katakana, and kanji. The limited ability of the Japanese language makes it difficult for students to pour ideas into sakubun.

Based on the results of initial observations that researchers do in class XI Accounting SMK Negeri 18 Jakarta, generally the students in learning to write sakubun using a particular package of books containing the grammar such as sentence patterns, vocabulary, examples and narrative exercises. This learning about sentence patterns and vocabulary first, then discuss the example sakubun together and ask students to do the exercises before making sakubun own. Such teaching seems monotonous because it lacks opportunities for students to grow. Students are not given the opportunity to share information, opinions, and can not learn from each other because they only use the knowledge and linguistics they have. Students become less interested in learning sakubun writing because of monotonous teaching. The next problem concerning the students who write below average ability to write in sakubun writing is 70 . This is because students have difficulty in pouring ideas. Generally they have difficulty in the stage of determining the theme, composing sentences, lack of grammar, and so on. Such difficulty faced by the students so that they can not convey the idea well, even they are reluctant to write sakubun. This is also inseparable from the role of the teacher as a transmitter of learning materials to write sakubun. The learning of writing skills that has been oriented to the use of textbooks and knowledge of Japanese, while the process of learning the ability to write sakubun often ignored the teacher.

In addition to teaching that is oriented only on the use of the package book, the lecture method used by the teacher is not able to motivate the students to receive the taught material. In fact the problem is closely related to the learning media used by teachers. Less innovative learning media causes students less interested. After submitting the material directly assigned students write sakubun, but students are still confused pour ideas in writing sakubun it. This difficulty causes the low quality of writing sakubun students both on aspects of content and linguistics.

The existence of the gap between hope and reality is a problem in learning to write sakubun, it would be wise if the Japanese language teachers see and try alternative learning media that can deliver students to achieve the expected results and can follow the learning process with fun. The gap is caused by the learning done so far oriented to the use of the book package and other techniques that have been done is the technique of translating sakubun Indonesian into Japanese, but the results obtained are still not maximal because students are not required to put their own ideas and ideas, while the teacher focuses only on linguistic knowledge.

To deal with the inability to write sakubun students, researchers offer one of the alternative media in learning to write sakubun Japanese language by using the media image series. This lesson emphasizes the stage of organizing the writing of a composition, correct grammar, and the appropriate use of vocabulary for writing sakubun. In addition, students also learn how to use the serialized drawing media to generate compelling articles with images that support the essay. Initially students were introduced to the writing organization sakubun include deeds, characterizations, background, and point of view. Once students know and understand the organization, students can automatically write sakubun or story with a good and correct flow. The organization of sakubun is the background, the peak, the problem solving. Gradually, with the organization writing sakubun, students understand and can write sakubun or story better. After that, students are invited to write sakubun in a structured manner with the correct grammar according to the sequence of stories on the media drawing series. With this grammar learning, students are invited to learn the grammar by checking the results of his writing with peers. Students also learn to visualize their sakubun writing with appropriate drawings that appeal to both the writing student and the reader.

Taking into account the problem in the achievement of meaningful learning, the author wishes to carry out action research to improve the ability to write narrative in Japanese through the medium of serial images. This learning uses four language skills based on writing skills. The author wants to examine whether the learning media used can achieve meaningful learning in learning to write Japanese narrative. 
Writing ability is an activity in pouring ideas or ideas, thoughts, or feelings are actively productive in the form of symbols of writing so that messages conveyed easily understood by others. Smith suggests that writing is rather like recycling paper, you give the texts you have read another life through the way you reshape them. Writing is an active productive activity that someone does in pouring ideas and feelings systematically through writing so that messages and information conveyed easily understood by readers. Writing is also a capability that is able to document ideas, views, inventions, official documents, and others. Writing skills require greater accuracy and mastery than other language skills. The ability to write not only express ideas for communication purposes in the form of writing but also requires the mastery of grammar or good grammar so that meaning is absorbed according to the author's intent.

One of the writing activities taught in Japanese language learning is writing sakubun or narration. Narrative is a form of writing that seeks to create, narrate, coupling the actions of human actions in an event chronologically or that take place in a unity of time (Akhadiah, et al., 2012: 2). Narrative is a story based on the sequence of events or events experienced by the character in accordance with the time or atmosphere. Narratives aim to convey or tell a series of human events or experiences based on developments over time. Semi suggests narrative features as follows: a) a story about a human event or experience, $b$ ) events or events conveyed may be events that actually occur, may be merely imaginary, or a combination of both, c) based on conflict because no conflict is usually unattractive, d) has an aesthetic value because the content and manner of delivery are literary, especially fictional narratives, e) emphasizes the chronological order, and f) usually has dialogue (Semi, 2003: 2).

One of the subject matter taught in SMK Negeri 18 Jakarta is Japanese. Based on the observation that the ability to write Japanese language narration of students of SMK Negeri 18 Jakarta is far from the standard of assessment expected. This fact shows that the Japanese language teaching in school has not been handled properly. Teachers and students have not been able to optimize the learning process, especially in writing narrative so that the expected results are not in accordance with the objectives of learning. So far, the learning of narrative writing is still done traditionally by emphasizing the students' writing, not on the process. Finally the narrative writing activity is considered to be a burdensome one so students do not have narrative writing experience. Behind the above demands, we get some problems. Firstly, teachers and researchers find it difficult to determine the right learning media so that it impacts students' attitudes during learning. Second, monotonous teaching as it is based on the package book. Third, teachers only focus on the linguistic knowledge of students.

It was also supported by initial test results in Accounting Class XI. Based on the analysis results, identified several problems in the Japanese language narration of students. First, the story ideas are made less developed in the narrative and less relevant to the topic of the story. Second, most of the contents of the writing has not depicted the ideal form of narrative, especially in narrating deeds, characterizations, backgrounds, points of view, and grooves. Thirdly, the resulting narration is irrational due to many grammatical errors, punctuation, and word separation. Fourth, the vocabulary of students is very minimal. Fifth, of all students of class XI which amounted to 40 people given initial test, 30 or about $75 \%$ has not reached the value of Minimum Criteria of Completeness (KKM), which is 70 . Therefore, the ability of students in class $\mathrm{X}$ in writing narrative needs to be improved.

Improved narrative writing skills can be done in various ways. Researchers choose and design the learning media in accordance with the conditions encountered. One of them by using the media image series. Media images can be grouped into visual media, visual media is a media that only rely on indrapenglihatan. This visual medium features a still image like a movie strip, photo slides, glow images, paintings, and prints. There is also a visual media that displays images or moving symbols such as silent films, and cartoons (Djamarah Bahri Syaiful and Zain Aswan, 2010: 124). The image media is an image-shaped tool used in learning activities to convey information or messages. The serialized image media is a visual medium that contains the sequence of images, between one image with another interconnected image and an event. Serial media can assist students in composing what 
they want to say as it is arranged in sequence from the beginning of the event or event to the end. Serial images also serve to help students understand and direct what will be said.

\section{METHODS}

This research is an action research. This study aims to find and describe the process of learning to write Japanese students' narrative that includes objectives, media, procedures, materials, the role of teachers and students, and the assessment of Japanese language narrative writing. This action research was conducted at SMK Negeri 18 Jakarta and involved class XI Accounting. The study took place on the even semester of the academic year 2016/2017, ie March to April 2016. The model of action research used is Kemmis and McTaggart model. Stages of this research include four stages, namely planning, action, observation, and reflection.

The action research model used is the Kemmis and McTaggart model. The model of action research according to Kemmis and Mc Taggart is the development of the basic concept introduced by Lewin. This action study consists of two cycles. Stages of action research on a cycle include four stages, namely the stages of planning, action, observation or observation, and reflection. The four components are done in one cycle. However, action and observation are two activities that are inseparable and done in one time. In this study, the cycle continues and is terminated if it is sufficient to meet the research objectives that have been set.

\section{RESEARCH AND DISCUSSION}

Researchers conducted preliminary studies in several ways so that problems encountered in learning narrative writing can be identified. The way that is done is the observation and charging questionnaire. Observations made to know the learning process that occurred during this time in the classroom. The difficulties associated with the writing of the narrative of the student are: 1) the notion contains less events or events that describe a story, and less relevant to the topic of the story; 2) most of the contents of the writing have not depicted the ideal form of narrative especially in describing deeds, background, point of view, and groove, 3) the resulting narration is irrational due to many grammatical errors, the use of punctuation, and capital letters, 4) the vocabulary of students is very minimal.

In addition, researchers also asked students to fill out a questionnaire that was used to find out the students' difficulties in writing the narrative. The questionnaire results show that students have difficulty in writing narrative. The difficulties are: 1) describes the activity, 2) describes characterization, 3) determines the background, 4) determines the point of view, and 5) determines the flow. The test results show that out of forty students only eleven students can create narrative essays based on fabrication, characterization, background, point of view, and groove.
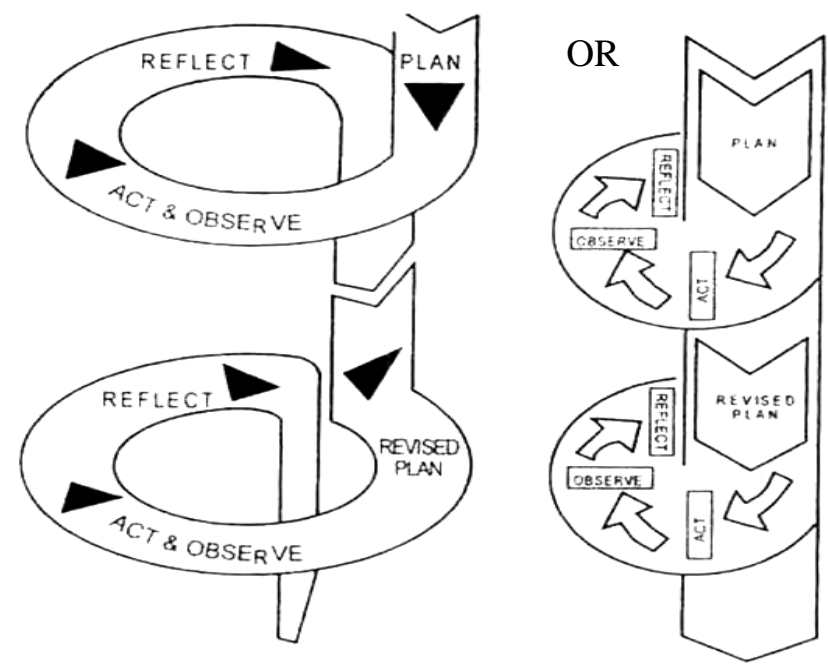


\section{Picture 1. Model of Kemmis and McTaggart}

in the planning phase, the researcher made the learning design based on the classroom conditions and facilities available in the school. In the design, researchers linked the learning materials of serialized languages, in particular writing narratives using the serialized image media included in the learning model. At this stage, the researcher makes a lesson plan for the implementation of the action that is carried out in accordance with the problems obtained during the initial reflection, ie the low writing of the student narrative. In addition to planning the implementation of learning, researchers also prepare tools, learning resources, learning materials, rubric writing skills, and sheets of observation to support learning activities. Teachers and collaborators plan meeting schedules and implementation schedules before the first cycle is implemented. This planning was conducted four times. The first planning of the planning / design of learning narrative writing. The second meeting concerning the implementation of action / preparation of narrative structures. The third meeting on the observation / development of narrative writing. Fourth meeting on reflection / revision.

In the implementation stage of learning on the material or basic competence on writing narrative by applying the action through the medium of the series image according to the planned implementation of the previously arranged learning. The teacher performs a preliminary test that aims to determine the initial capability, which results will be compared with the first cycle test and the second cycle test. The next activity, the teacher provides learning materials and asks students to observe the media of the series image. The teacher asks the students to identify the context in the image medium such as describing the situation / topic, background, figure and plot. In the observation stage, the teacher looks at and notes whether the action is carried out in accordance with the planning. Teachers collect data in the form of observations of action scenarios over time and their impact on student learning outcomes. Data collection in this stage is done with observation form in the form of observation on action scenario from time to time, and its impact on student learning outcomes. The data describes the liveliness, enthusiasm of students, and others. The teacher checks the narrative script created by the students, while the collaborator monitors the learning activities by filling out the observation sheet in the form of a questionnaire.

In the reflection phase, the teacher analyzes the student's narrative script. After that, the teacher and students discuss the students' narrative writing. Students are asked to give an opinion on the results of his friend's narrative. The opinions expressed are not only related to the narrative structure but also the grammar, vocabulary, punctuation, letter writing, and word separation. Students accompanied by teachers improve the writing of narrative based on the opinion of his friend.

Teachers do reflection by drawing conclusions about the learning activities that have been implemented with respect to the material obtained from the observation. Teachers and collaborators reflect on field notes and observe the results of narrative writing through serialized media from planning, action, observation, to reflection. The results of observations that have been collected are analyzed. If the value of narrative writing is lower than the indicator set, the researcher assumes that the student's narrative writing skill has not improved so that improvement is needed for later planning. In the reflection phase, identification of the narrative writing points that have not been and has been achieved. The shortcomings in learning narrative writing through the medium of radiographic images were discussed with collaborators and improved in cycle II as the completion of cycle II planning. The second cycle of action research is not much different from cycle I. In this cycle, the research stages are improved so that there is an increase in narrative writing skills.

Data analysis technique used is triangulation. Triangulation is a technique of examining the validity of data that utilizes something else (Moleong, 2007: 330). For example, the information obtained by teachers compared with the existing theory. In addition, data validation was conducted in three stages, among others: 1) researchers and collaborators in the form of field notes and notes of collaborators as input and comparison, 2) the results of the exercise and the task of research subjects (students) in the form of worksheets and the results of his work, 3) various references and sources of readability that can be accounted for. 
Pre-tests were conducted on Thursday, March 03, 2016. At this stage, students first fill in and collect questionnaires. After the pre-test, the average score obtained by students is still low at 57.7. The pre-test value is still far from the standard set value of 70 . The criteria for the ability to write the initial test narrative include: excellent criteria of 100-90 very good, good criterion value 89-80, criteria enough 79-70, criteria less $<70$. The result of observation of student activity at the beginning of the test that is very good criterion not exist or $0 \%$, criterion either not exist or $0 \%$, enough criterion 10 person or $25 \%$, criterion less 30 person or $75 \%$. Assessment of Narrative Writing Skill from 40 students obtained $4.6 \%$ theme theme, $5.2 \%$ flow, $5.7 \%$ action, $6.4 \%$ characterization, $7.6 \%$ background, $7.3 \%$ perspective, $3.9 \%$ vocabulary , $5.4 \%$ grammar, $5.2 \%$ vocabulary, $5.5 \%$ punctuation, $5.1 \%$ word splitting. Assessment is presented in the following diagram.

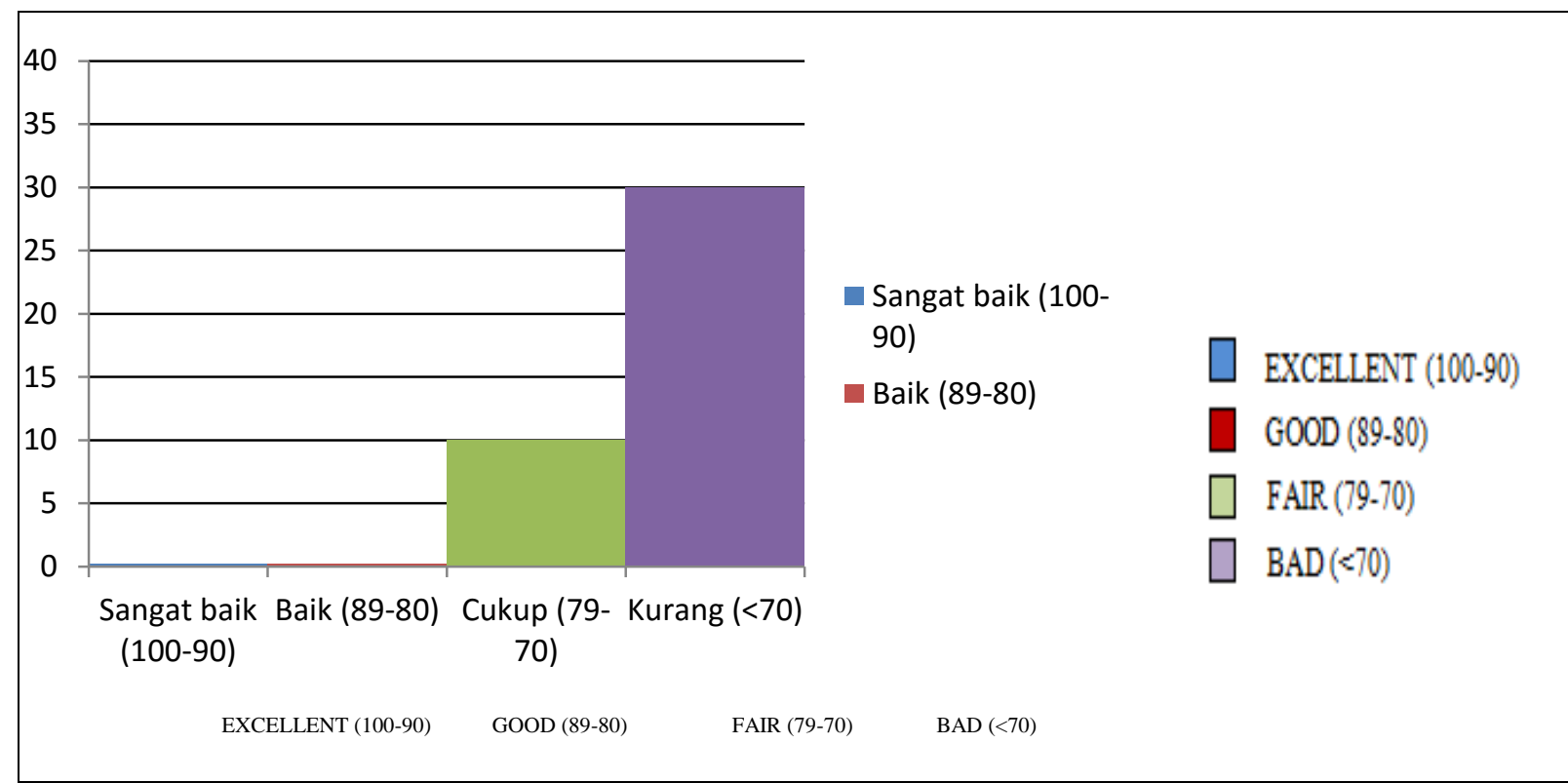

\section{Diagram 1.1 Pre-test Assessment Results}

Based on the results of the above pre-test data can be concluded that the activities of students during the process of learning to write Japanese narrative has not shown the maximum results, then compiled a plan of action research directed at improving the ability to write Japanese narrative through the media series image. The medium of this series image is done so that the ability to write student narratives can increase. Description of Cycle I

The assessment of writing Japanese narrative in cycle I was done by two assessors. The first appraiser is the teacher of class XB itself (researcher), while the second appraiser is the collaborator in this research. It is hoped that with the existence of these two assessors will be obtained an objective assessment results. Aspects assessed are: 1) the content of ideas in the form of themes and plot, 2) organization in the form of deeds, characterizations, background, and point of view, 3) linguistic form of grammar and vocabulary, and 4) mechanical form of punctuation and word separation. The theme and the plot have a maximum value of 20. Characterization, background, deed, and point of view have a maximum value of 40 . Grammar and vocabulary have a maximum value of 20 . Punctuation and word separation has a maximum value of 20. Thus, the maximum number of values for all aspects in writing Japanese narrative is 100.

The result of the recapitulation of the student writing narrative writing in cycle I (appendix VII) obtained the average score of students for the whole aspect of 68.5. The lowest score of students is 50 , whereas the highest score of students is 85 . Although the score obtained by students in cycle I increases in theme, deed, grammar, and vocabulary compared to the values obtained in the pre-test but the value in cycle I is not sufficient the standard value set by KKM is 70. The average score that students get for the content of ideas in Japanese narrative is 12.4. The maximum value of the content is 16 . The average value of the theme is 5.7 . The maximum value of the theme is 7 . The average value 
of the flow is 6.8. The maximum value of the flow is 9. The average value that students get for the organization is 29.1. The maximum value of the organization is 35 . The average value of the action is 6.2. Maximum value of action is 8. The average value of the characterization is 7.4. The maximum score of the characterization is 9. The average value for the background is 8.0. The maximum value of the background is 9. The average point of view in Japanese narrative text is 7.6. The maximum point of view is 9 .

The average score that students get for language is 13.5. The average value of grammar is 6.7. The maximum value of grammar is 9. The average score that students get for vocabulary is 6.7 . The maximum value of the vocabulary is 9 . The average mechanical value is 13.5 . The maximum value of punctuation is 9 , while the maximum value for the word separation is 8 . Overall the acquisition of the student score for the result of writing Japanese narrative on this cycle I can be observed at appendix VII.

Based on the recapitulation of the average value of writing Japanese students' narration in cycle I it can be concluded that the value obtained by students is still lacking. It is based on the maximum value that students get for each aspect. The average score obtained by students is still less when compared with the maximum value contained in the Japanese language narrative writing score. Less aspect values include theme, flow, deed, grammar, vocabulary, and word separation. In addition, there are also increased aspect values in writing Japanese language narratives including characterizations, background, point of view and punctuation.

The criteria of the ability to write Japanese narrative include the criteria of excellent value of 100-90, good criterion value of 89-80, sufficient criterion value 79-70, criteria less score 70 down. Observation results of student activities during cycle I, namely: very good criteria no criteria either 7 people or $17.5 \%$, criteria enough 19 people or $47,5 \%$, criterion less 14 person or $35 \%$. So easy to know ability of write narration cycle I, presented assessment in the form of the following diagram.

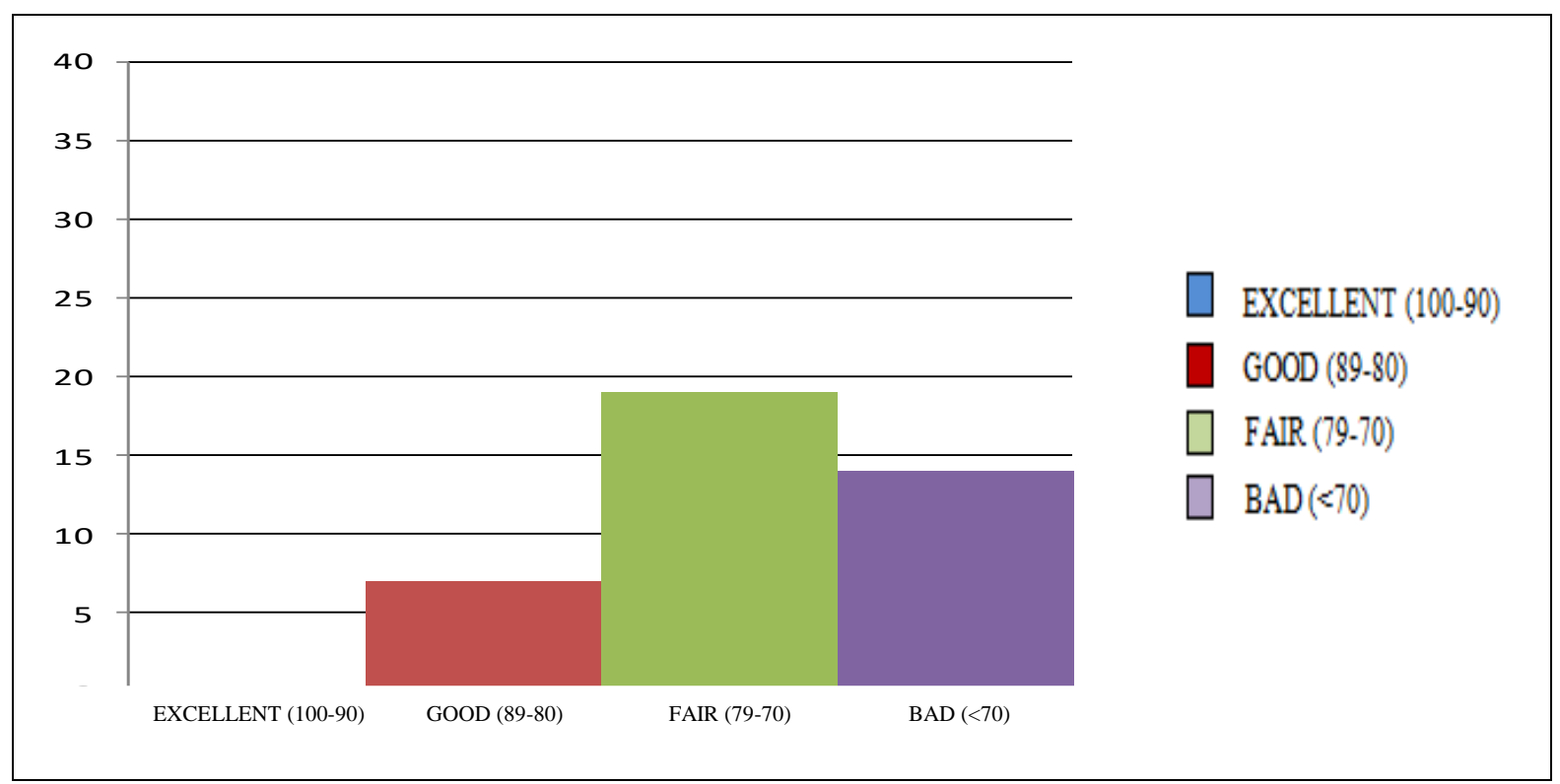

\section{Diagram 1.3 Cycle Conclusion Evaluation Results I}

At this stage students finish writing the narrative well and have the ability to choose and direct the internal process in learning. The following is an assessment of the ability to write narrative cycle II in the form of the following diagram. Diagram 1.4 Result of Cycle Narrative Writing Skill Assessment II. Based on the recapitulation of the average value of writing the narrative of students in cycle II concluded that the value obtained by students is good. It is based on the maximum value that students get for each aspect. Increased aspect values include theme, plot, action, characterization, background, point of view, grammar, vocabulary, punctuation, and word separation The average score is good when compared to the pre-test and cycle I. The average grade of the theme is 7.7 and 
the mean value of the groove is 8.4. In addition, the average score of action is 7.6 and the average score is 8.6 and the mean value of the background is 8.7 and the viewing angle is 8.6. The average vocabulary score is 8.4 . The average value of grammar is 8.3 and the average value of punctuation is 8.4. Finally, the average value of word separation is 8.4.

To be easy in knowing the skills of writing narrative cycle II, the following presented the assessment in the form of the following diagram.

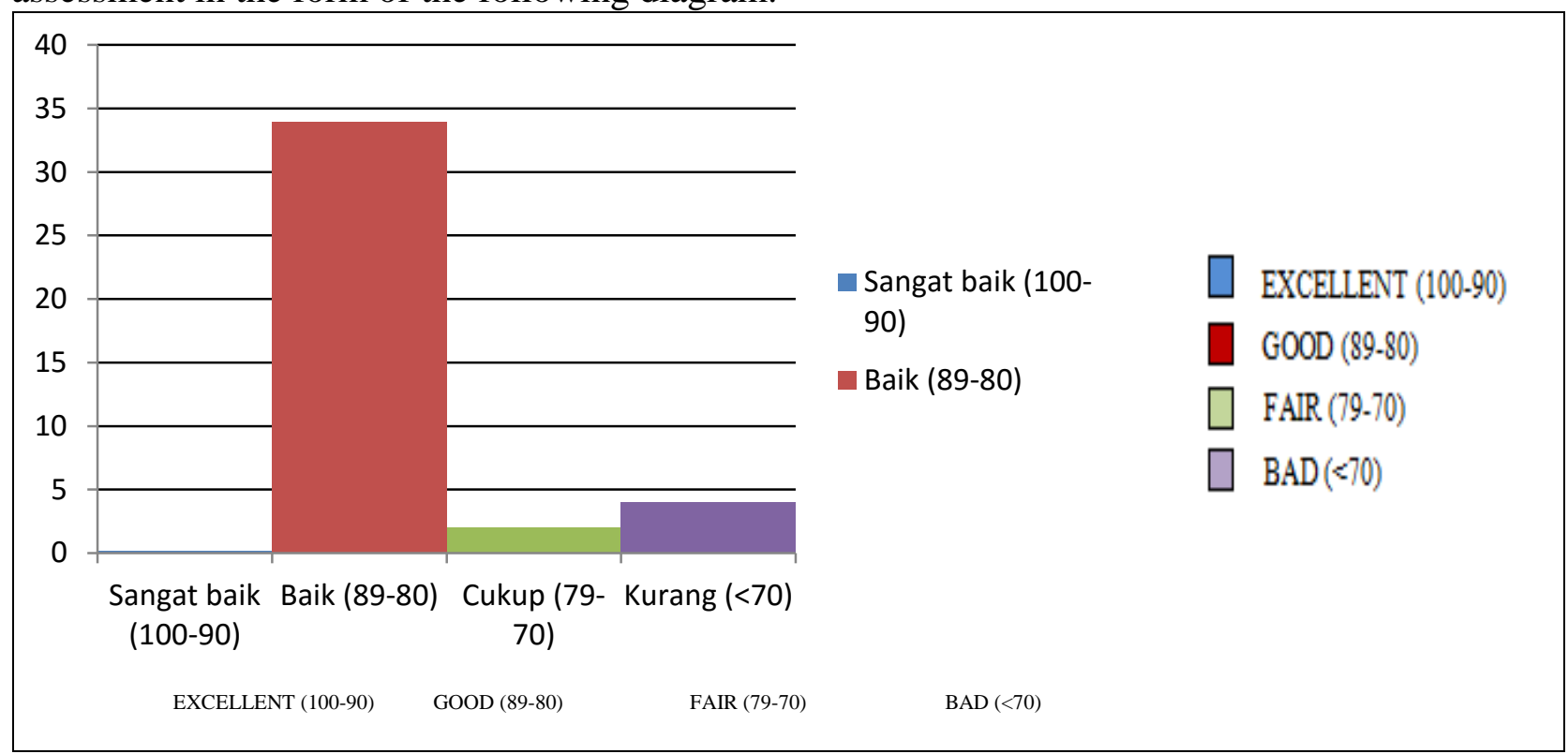

\section{Diagram 1.5 Cycle Conclusion Evaluation Results II}

Criteria for the ability of writing narrative cycle II include excellent criteria with a value of 10090 , good criteria ranging from 89 to 80 , enough criteria with a value of $79-70$, while the criteria is less with a value of 70 down. The result of observation of student activity during cycle II, that is: no students get very good criterion, criterion either 34 person or $85 \%$, enough criterion 2 person or $5 \%$, criterion less 4orang or $10 \%$.

\section{RESULT AND DISCUSSION}

The results of the comparison of the ability to write Japanese students' narrative during the initial test, cycle I, and cycle II are presented in the following diagram.

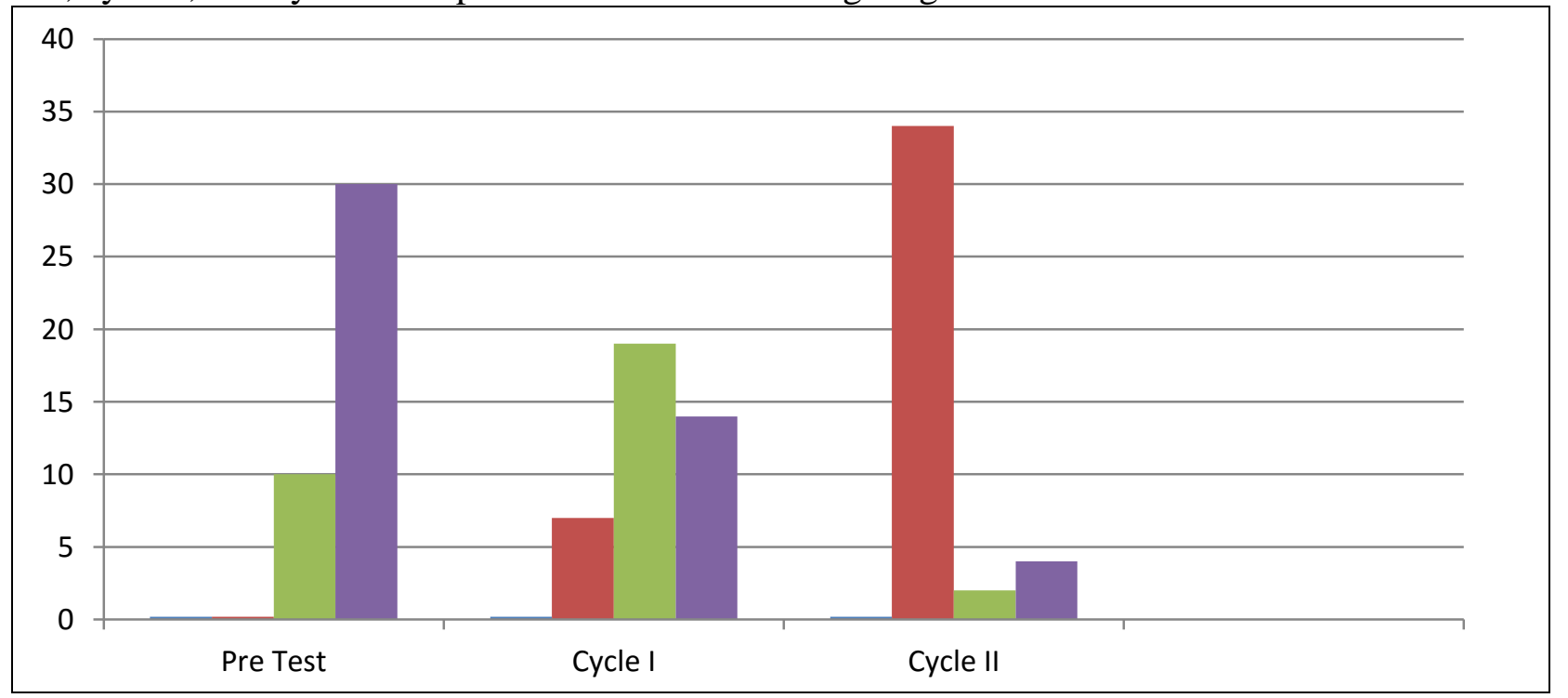

Diagram 4.6 Comparison Result Initial Test, Cycle I, and Cycle II 
The conclusion of writing the narrative of Japanese language through the media of the series of students from the final activity of learning can be seen that this cycle I has not succeeded because students are stated less as many as 14 people or $35 \%$. The lowest score is 50 , while the average of 68.5 has not reached 70 of the established rating standard.

Looking at cycle I, in the implementation of cycle II, improvements were made, especially the improvement of narrative writing skills. The acquisition of value of content, organization, vocabulary, language usage, and mechanics in cycle II increased significantly, students no longer got scores with less criteria. Therefore, on the second cycle increased by 34 people get either criteria or $85 \%$, enough criteria 2 people or $5 \%$. Starting from the data about student learning outcomes that experience a change toward the improvement of the cycle I and cycle II can be concluded that the application of serial images can improve the ability to write Japanese narrative.

\section{CONCLUTION}

Based on the results of research that has been done, can be drawn conclusions based on research questions, namely

1. The process of improving the ability to write Japanese language narration through the media of series images. This process can be seen from the ideas expressed by students looking slightly different from the results of the narrative writing on the pre-test. New ideas using serialized media give students enough confidence to develop Japanese narrative essays. Their imagination began to play a role in forging ideas for story ideas. The language they use leads to the imagination of an object and unleashes the idealist ideal of thought or always suggests that it is okay to avoid being reprimanded by teachers as they have been doing. Through the medium of series image, student motivation becomes high enthusiastic in writing Japanese narrative. This can be compared when the first time learning narrative writing, the student looks passive. Students' attitudes become positive for the ability to write Japanese narrative through the medium of series images.

2. The result of improving the ability to write Japanese language narrative through the medium of series image. Increased ability to write Japanese students 'narratives through the medium of series images is learned through the students' daily experiences. The assessment instrument is based not only on Japanese language narrative only but also on observation sheets, and field research notes. In addition, the assessment is also seen from the writing of Japanese students' narrative that increases from cycle I and cycle II. This assessment can be seen from the narrative writing that includes: a) content in the form of theme and flow, b) organization in the form of deeds, characterizations, background, and point of view, c) use of language in the form of grammar, and vocabulary, d), letter writing, and word separation. In the first cycle, the level of writing ability of Japanese students' narrative through the media of serial image was not satisfactory because it still has not reached the standard of assessment which is determined. This is based on the initial test of the acquisition value of the lowest narrative writing ability 42 and the highest score 78 and the average grade grade 57.7 . In cycle I the lowest score of 50 and the highest score of 85 and the average grade grade 68.5. Improved the ability to write the Japanese language narration through the series of drawing media in cycle II by making improvements, especially on the narrative structure and emphasize the step of increasing and deepening on aspects that students have not mastered, especially on vocabulary and grammar. In the second cycle there is an increase in the ability to write Japanese narrative of students who get low grades. The lowest value obtained is 66 and the highest score is 88 and the grade is 83.2. The average value of the ability to write the Japanese language narrative through the medium of series image is on the initial test $57.7,68.5$ cycle I, while in cycle II 83.2. 


\section{REFERENCE}

Akhadiah, Sabarti., Maidar G. Arsjad and Sakura H. Ridwan. 2012. Development of Writing Skills Bahasa Indonesia.Jakarta: Erland.

Moleong, Lexy J. 2000. Qualitative Research Methodology. Bandung: Teens Rosdakarya.

Syaiful, Djamarah Bahri and Zain Aswan. 2010. Teaching and Learning Strategies. Jakarta: Rineka Cipta.

Semi, Atar. 2003. Writing Effectively. Padang: Angkasa Raya.

Smith, Hazel. 2005. The Writing Experiment: Strategies for Innovative Creative Writing. Australia: Allen \& Unwin.

Sudjianto and Ahmad Dahidi. 2004. Introduction to Japanese Linguistics. Jakarta: Kesaint Blanc. 